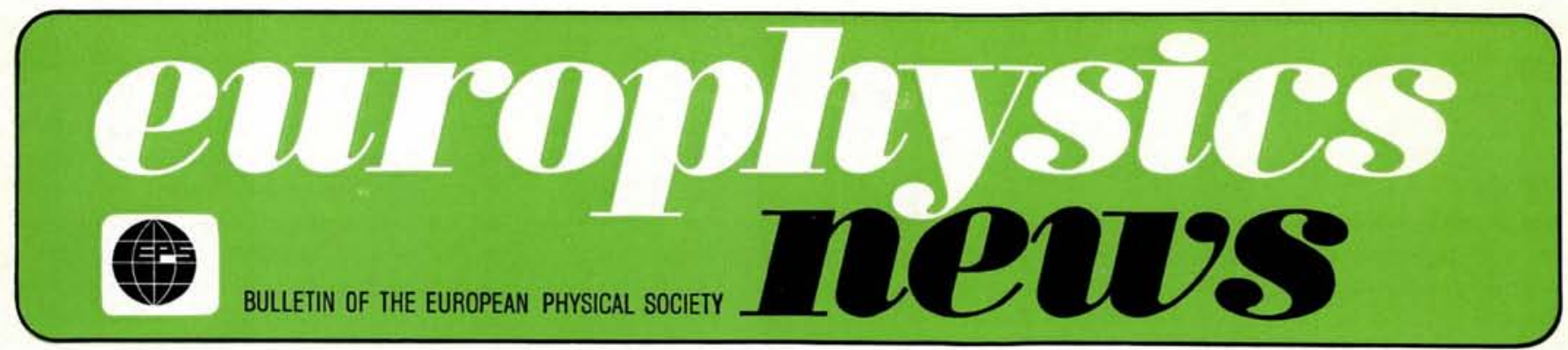

\title{
Hunting Jobs for Physicists
}

A few years ago, the Grenoble section of the French Physical Society (SFP), considering that the problem of finding employment for physicists was important enough, decided to start an activity called "Bourse de l'emploi des Physiciens", In fact we had no idea about what to do, how to do it and about the possible results. But now we can say that it has been successful, at least as an experiment in itself if not as an actual employment agency.

To describe this activity, it is necessary to start by an account of the boundary conditions in our country, because they may differ from those in other European countries. First of all, the higher education system is divided into two distinct branches: the "Grandes Ecoles" in principle prepare students to become engineers, and the Universities give them a more fundamental culture either for them to become mainly secondary school teachers, or without any professional purpose. To enter the "Grandes Ecoles ", one must follow after the baccalaureat (the end of secondary school) special classes, held in the secondary schools and not in the Universities, and be submitted to a severe competitive examination. On the contrary, Universities legally must admit any student having his baccalaureat.

So the leaders of industrial life who are graduates of these " Grandes Ecoles " are tempted to engage in their companies people having a similar training for many evident reasons, one of them being that those students have been selected. There is also a tendency to forget that Universities, although not selective for would-be students, do not give the graduation title to anybody. As the research labs in fundamental physics are more connected with Universities than with "Grandes Ecoles ", with a few exceptions, anybody is tempted to assume research students have graduated only from Universities, even if half of them come from "Grandes Ecoles".

It must be added that in the sixties, the research institutes of Universities, Centre National de la Recherche Scientifique, and other government institutions were developed rather fast - at least compared to what was seen before or after. So it was easy for students after their Ph. D. to get permanent positions in those institutions or in the Universities; new research students were given fellowships, and the labs were living as if such an exponential growth would never end.

In the seventies, when the crisis suddenly came, we had to find jobs for research students after their $\mathrm{Ph}$. D.; first of all because, even if not formally, we did have obligations towards them; and even if cynically we think that it is their problem, we cannot hope to engage new research students to give some life to our labs, if we are not able to solve the problems of the present ones.

In fact, this is nothing else than discovering our collective responsibility as physicists. If we are physicists not only because this happens to be our job, but if we really like it, and if we believe in physics - and more generally in science - thinking it may be one of the greatest acquisitions of human culture, we cannot even be happy if society gives us good working conditions. We really believe we must have an influence on society, not only through a technical output, but mainly by giving people a way of thinking which can be used with profit anywhere.

When we realized this, we had the key advertising idea to "sell the product". Our Grenoble group started by meeting some industry managers, and by publishing a small booklet designed to present the technical and intellectual training given to physicists in local labs; at the same time a

\section{P. Averbuch, Grenoble}

parallel action was started by the Commissariat à l'Energie Atomique which was anxious to find jobs for the many young people to whom it gives $\mathrm{Ph}$. D. grants. A close cooperation was started between these two actions, made easier by the fact that the two initiators are colleagues having had professional cooperation some years ago.

We started visiting industry managers, presenting them biographical statements about candidates for industrial positions, and getting them to publish vacancies, to advertise in the labs. Although the techniques differed between the C.E.A. and the Grenoble Section of S.F.P., there was some overlapping, and we cooperated continuously by exchanging information. But mainly we had a common idea, that such an enterprise must not be an office somewhere, but must be an emanation of the laboratories themselves, so that the relationship between the job hunters, the candidates and the industry managers is as clear as possible. The pressure exerted by the candidates, combined with our responsibility to the community of physicists when speaking to managers more or less on behalf of the Physical Society, insured an equilibrium in the working of such an activity.

In fact what has been done is nothing more than a generalization of

\section{Contents}

Hunting Jobs for Physicists .

Letters to the Editor

Energy and Physics, Scientific programme

Society News

EPS Grants to Young Physicists

for the Bucharest Conference
1 
what the Professor in ancient time was doing when finding a position for his student in the only company he knew. And it is this continuation of an old tradition - on a bigger scale which makes this activity valuable per se and not only punctually efficient.

The most important result, at least for the people engaged in this jobhunting activity, who have themselves permanent University or Research Institute positions, was to discover that the world of industry is understandable to us, that it has its own problems, sometimes fascinating, and that the industry managers are not as hostile to the fundamental research world as we believed. In fact, after having tried to understand their problems, having realized that they tried to understand ours, and having exchanged such information, we admit- ted the possibility of speaking a common language.

This may be because industry managers are, apparently more than us, sensitive to the problems of the society, which have more direct influence on their pratical activity than on our purely intellectual one. As we believe in our job, they belive in their own, which does not mean that all of them agree with the whole social organisation.

But believing in industry, they are obliged to think that the present problems of the society will not be solved by a return to the delightful palaeolithic times, but by an improvement of techniques for solving more and more human problems.

And they know that the solutions of these problems cannot be elsewhere than in the progress of know- ledge, that is in research institutions. Of course, this is also our idea and even if their situation makes them more sensitive to immediate results, the possibility of a general consensus exists. What may be more important than to have obtained jobs for about a hundred people, is the effect our activity may have had in improving the relationship between those whose job is to increase the collective knowledge of the world and those whose job is to use this knowledge to satisfy the needs of men.

Acknowledgement : this experiment is partially supported by Commissariat à l'Energie Atomique, Centre National de la Recherche Scientifique, and many Grenoble research labs, without whose material and moral help it could hardly have been started.

\section{Letters to the Editor}

Sir,

In European scientific conferences which fortunately become from year to year more numerous the working language which has naturally imposed itself is English.

This is a fact accepted by all, for the simple reason that the experience has shown that, the things being as they are, this was the best, if not the only means of communication between scientists. No other consideration can validly be opposed to this decisive criterium of efficiency.

We realize, of course, that the "Conference Language" is nothing but a horrible "broken English" and we are grateful to our British colleagues that they support that their fine language is martyrized. (It may be that we Frenchmen would not have the same patience in inverted circumstances.)

But the generalized use of English brings for all the non-English-speakers difficulties at one and the same time of expression and of comprehension quite unequal from one nation to another. It is thus clear that the Scandinavians, Dutchmen and Germans, for instance, generally speak English with much more ease than the Latins. Nevertheless we are happy in France to state the notable progress which has been accomplished by the young in our laboratories, who manage now to be no more stopped in international relations by the barrier of language. But this requires of most of them at the start of their career a very large effort and, in spite of that, very few are in a position to profit fully from the first conferences which they attend.

On the other hand one must mention the enormous advantage from which quite naturally benefit the English scientists for the fact that they never know the feeling of frustration to follow badly, because of the language, a lecture essential for their work or not to be able in a discussion to communicate exactly and rapidly their ideas.

Of course, we do not feel any bitterness confronted by this state of fact. It is still necessary that all should do their best never to aggravate the situation, and I wish to address a request to all our colleagues and specially to our British friends. It is not rare, actually, to state that in a series of lecturers of different nationalities expressing themselves in English, the one we follow with most difficulty is... the Englishman! This is why I would ask those who take the floor in a European meeting to have always present in their mind until the end of their speech that the majority of their listeners need to hear not only snatches of phrases but all the words they pronounce and they should remember that from hearing to comprehension the process is long for those who know a language badly. Could the British, before a European audience, for once borrow the bad manners of certain continental tribes: speak loudly and distinctly, articulate each word, even make some gestures, lose provisionally the sense of humour so as to act as if they consider what they are saying to be important and to let themselves go in wishing to convince their listeners?

\section{A. Guinier, Paris}

\section{Sir,}

I read with great interest the article about the European Science Foundation in the March issue of Europhysics News. Being a member of an international research group I very often encounter problems connected with several of the principal objects that are quoted from the statutes of the ESF. In particular, I very often get letters from people who would like to work in our group for a certain period and who wonder where they could apply for financial support for such a purpose. We certainly know of a number of such agencies, but it would seem to me that it would be very desirable if either ESF or EPS could make an inventory of such organisations which award fellowships for pre- or post-doctoral work, or support scientists visiting other institutes for shorter or longer periods.

Jean-Louis Calais, Uppsala 